

La reconciliación: reto ético y político en el contexto colombiano 


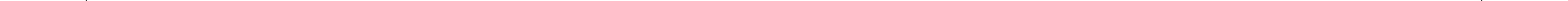




\title{
La reconciliación: reto ético y político en el contexto colombiano
}

\author{
Por Mauricio García Durán S. J.*
}

Resumen: El artículo se aproxima al debate sobre la reconciliación a nivel internacional, en toda su complejidad, para lo cual resalta los elementos que pueden contribuir a la construcción de una paz sostenible y duradera en Colombia, a través de cinco interrogantes: a) ¿Por qué trabajar por la reconciliación?, que pretende presentar las razones para comprometerse en su promoción. b) ¿Qué podemos entender por reconciliación?, que muestra los desarrollos conceptuales que permiten responder a la complejidad que supone promover la reconciliación tras un conflicto largo y degradado. c) ¿Quién(es) es (son) agente(s) de la reconciliación?, que señala los actores que participan, en particular, las víctimas. d) ¿Cómo avanzar hacia la reconciliación?, que muestra los modelos de reconciliación que se pueden implementar. e) ¿Cuándo se puede avanzar en la reconciliación?, que indica la dimensión de temporalidad que esta implica.

Palabras clave: reconciliación, procesos de paz, justicia transicional, verdad y reparación.

\section{Reconciliation: An ethical and political challenge in the colombian context}

Abstract: The article seeks to make an approximation to the debate about reconciliation on an international level, in all the complexity that this implies, highlighting the elements that can contribute to the construction of a sustainable and lasting peace in Colombia. It is done by answering five questions: (a) why to work for reconciliation? Looking to present the reasons to engage in its promotion. (b) What can we understand by reconciliation? Showing the conceptual developments that make able to answer to the complexity that supposes to promote the reconciliation after a long and withered conflict. (c) Who are agents of reconciliation? Indicating the actors involved, in particular the role of the victims. (d) How to move towards reconciliation?, showing the models

* Sacerdote jesuita, ha realizado estudios de pregrado en Ciencia Política en la Universidad de Los Andes, y en Teología en la Universidad Javeriana. Cuenta con una maestría en Filosofía en la Universidad Javeriana, y un doctorado en Estudios de Paz, en la Universidad de Bradford, Reino Unido. 
of reconciliation that can be implemented. (e) When can we advance in reconciliation? Indicating the dimension of temporality, that promoting reconciliation implies.

Keywords: Transitional justice, Peace processes, Recontiliation, Truth and reparation.

Cómo citar este artículo: García Durán S.J., Mauricio (2018). La reconciliación: reto ético y político en el contexto colombiano. Revista Controversia, 211, 17-58.

Fecha de recepción: 16 de junio de 2018

Fecha de aprobación: 10 de agosto de 2018

\section{Introducción}

uando se intenta finalizar un conflicto armado como el que ha vivido Colombia, se plantea un asunto central: ¿cómo ajustar cuentas con ese pasado violento, con las múltiples heridas que este ha producido, con la ruptura del tejido social, resultado del mismo, y la polarización de la sociedad que se ha generado? En medio de un contexto así, la reconciliación aparece como uno de los posibles caminos para salir del laberinto y poder apostar esperanzadamente por un futuro compartido.

Sin embargo, nos enfrentamos a diversas e incluso opuestas comprensiones de lo que es la reconciliación, lo que dificulta la construcción sostenida de paz. Mientras para algunos la reconciliación es un sinónimo de impunidad y una estrategia social opuesta a las víctimas, para otros es una dinámica social que permite avanzar en la sanación de las heridas producidas por la guerra y promover un camino hacia la verdad, la justicia y la reparación. Por otro lado, algunos consideran que esta se vincula más a las dinámicas que favorecen las relaciones interpersonales y otros creen que facilita la puesta en marcha de procesos de carácter más colectivo y comunitario, que ayudan al ajuste de cuentas con el pasado. Asimismo, algunas personas estiman que este es un concepto recargado de contenido religioso, que no necesariamente contribuye con el pacto civil requerido para una paz sostenible, en tanto 
que otras piensan que, desde la experiencia de la fe, se puede consolidar una opción, que, al tener en el centro a las víctimas, promueve paz, reconciliación y justicia.

Es evidente que Colombia requiere dinamismos sociales, que le permitan hacer frente a las múltiples heridas dejadas por el conflicto y exorcizar los deseos de venganza de los distintos actores activos y pasivos de la guerra a lo largo de toda la geografía nacional. La existencia de un contexto tan polarizado como el colombiano es una expresión clara de la necesidad de promover procesos que nos permitan a todos los colombianos coexistir democráticamente y en paz, en una apuesta colectiva por un futuro más justo y equitativo, en el que todos y todas tengamos cabida. De ahí la importancia y pertinencia de un trabajo por la reconciliación.

Para avanzar positivamente en esa dirección, es necesario aclarar los conceptos y las prácticas que nos pueden ayudar a impulsar dinámicas reconciliadoras que aporten constructivamente a la sociedad colombiana. Los siguientes cinco interrogantes nos aproximan a una comprensión teórica y práctica de la reconciliación ${ }^{1}$, que son claves para planificar acciones y facultan la valoración de las experiencias de reconciliación promovidas en el país:

a) ¿Por qué trabajar por la reconciliación?

b) ¿Qué podemos entender por reconciliación?

c) ¿Quién(es) es(son) agente(s) de la reconciliación?

d) ¿Cómo avanzar hacia la reconciliación?

e) ¿Cuándo se puede avanzar en la reconciliación? ¿Cuál es su temporalidad?

1 Para mayor información, véase: Huyse (2003, p. 19) y Salter (2016, p. 2). 
Con este objetivo, el artículo se desarrolla en cinco partes, que buscan responder a dichos interrogantes, y termina con una conclusión, que permite sintetizar la aproximación alcanzada en torno al tema.

\section{¿Por qué la sociedad colombiana se debe comprometer con la reconciliación?}

El primer tema a tratar es la necesidad y pertinencia de la reconciliación para ajustar cuentas con un pasado difícil, que ha fracturado y dividido la sociedad colombiana durante un conflicto armado de más de sesenta años. Hay una serie de razones sociopolíticas que nos permiten acercarnos al aporte que la reconciliación puede brindar en la construcción de una sociedad en paz y sostenible para todos, en la que todos tengamos cabida.

\section{Razón 1}

Porque la reconciliación conlleva una ruptura con la dinámica de división y polarización, producto y resultado de una "guerra contra la sociedad" (Pécaut, 2001, pp. 15 y 19).

Cuando tomamos conciencia de que todo aquello vivido por la sociedad colombiana fue realmente una "guerra contra la sociedad", podemos percibir la necesidad clara de impulsar procesos sociales que reversen los efectos originados por esta guerra, que ante todo afectó a la población civil. Es por esta razón que el impulso de los procesos de reconciliación en distintos niveles sociales y ámbitos geográficos tiene sentido.

Con base en la información del Banco de Datos de Derechos Humanos del Cinep/PPP, podemos considerar los resultados de algunas investigaciones, que confirman esta dinámica de "guerra contra la sociedad". En la figura 1, que expone la comparación entre HECHOS de "acciones bélicas" (acciones entre combatientes) y aquellos de "infracciones al Derecho Internacional Humanitario (DIH)" (acciones contra la sociedad), se puede observar que, entre 1990 y 2017, las infracciones al DIH 
siempre fueron mayores que las acciones entre combatientes. En otras palabras, el conflicto armado colombiano reciente se caracterizó, entre otras cosas, porque la sociedad fue afectada prioritariamente, aún más que los mismos actores armados. Al presentar la síntesis de sus resultados hasta el momento del cambio de Gobierno, el Centro de Memoria Histórica (2018) ha constatado que, de las 262197 víctimas fatales, en sesenta años de conflicto armado (1958-2018), el $82 \%$ eran civiles y solo el $18 \%$ combatientes.

\section{Figura 1. Comparativo de hechos de acciones bélicas e infracciones al DIH (1990-2017)}

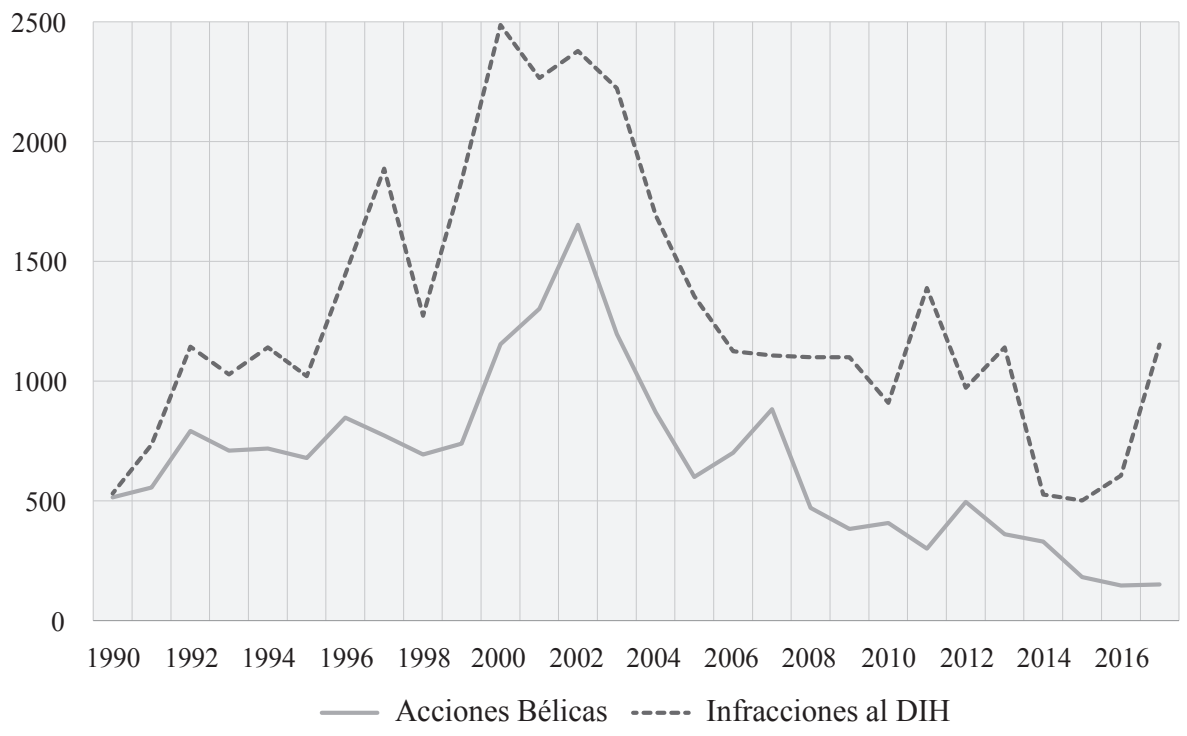

Fuente: Cinep/ppp. Base de datos de actores y dinámica del conflicto (1990-2017).

Esto coincide con las tendencias constatadas por el Cinep/PPP, expuestas en la figura 2, que compara las víctimas de las acciones bélicas y las infracciones al DIH entre 1990 y 2017. 
Figura 2. Comparativo de víctimas en acciones bélicas (combatientes) e infracciones al DIH (1990-2017)

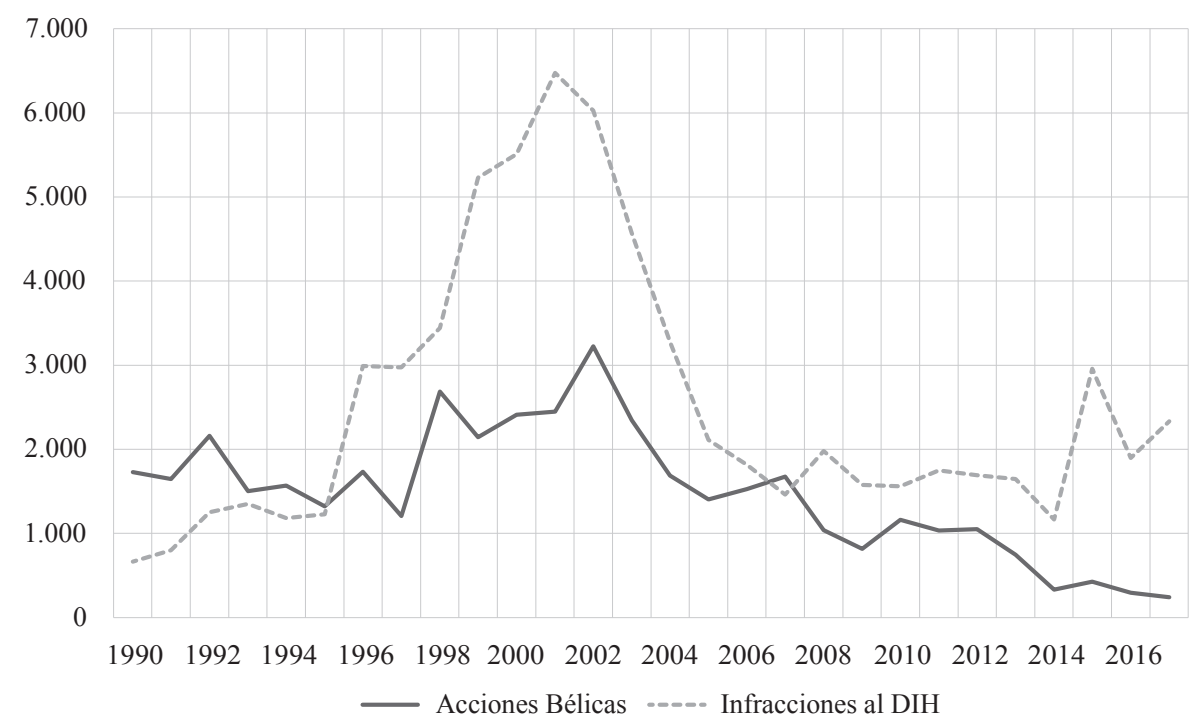

Fuente: Cinep/PPP. Base de datos de actores y dinámica del conflicto (1990-2017).

Esta realidad nos remite a una paradoja de la paz, como se pudo ver en el plebiscito aprobatorio de los acuerdos de paz con las FARC en octubre de 2016: el sí a los acuerdos ganó de manera holgada en aquellas regiones más afectadas por el conflicto armado, mientras que, en aquellas ciudades en las que menos se sintió el conflicto, ganó el No. Es decir, los sectores más victimizados se mostraron más proclives a la paz y a la reconciliación.

\section{Razón 2}

Porque las heridas que causan los conflictos (armados) necesitan ser curadas, para que no sigan reproduciendo ciclos de violencia y/o exclusión: la reconciliación puede ser una contribución a esta causa. 
El caso de Colombia presenta un conflicto prolongado y degradado, de sesenta años, que ha producido muchísimas heridas, gracias a las víctimas directas, que ascienden aproximadamente al $17 \%$ de la población colombiana. Como el Centro de Memoria Histórica (2018) lo ha mostrado recientemente, a través de la compilación de información de distintas fuentes, en sesenta años, el conflicto armado produjo 262197 víctimas fatales, 37094 secuestrados, 24518 víctimas de masacres, 80514 desaparecidos, 17804 menores reclutados o utilizados para la guerra y 15687 víctimas de violencia sexual. A ello, se suman 7677609 desplazados internos, la mayor cifra en un país a nivel mundial, según registra Acnur en 2017 (p. 64).

¿Cuáles son esas heridas que deja la injusticia política de un conflicto? Se han identificado diferentes tipos de ellas en los conflictos. Los planteamientos de Daniel Philpott (2012) ${ }^{2}$, al hablar de la ética de una reconciliación política, nos pueden ayudar a comprender las afectaciones de un conflicto como el colombiano:

1) El despojo de las víctimas de sus derechos, supuestamente garantizados por el orden constitucional y político del país.

2) Las heridas en el cuerpo y alma de la víctima, como son muerte, pérdida de familiares y amigos, despojo de bienes y pertenencias, violencia sexual, humillación, desplazamiento forzado, etc.

3) Muy frecuentemente, la víctima ignora el origen y circunstancias de la violencia que lo ha afectado.

4) El desconocimiento del sufrimiento de la víctima por sus conciudadanos, por ignorancia o por indiferencia.

5) El triunfante e impune desinterés y desprecio de la dignidad de la víctima por victimarios no derrotados.

2 A no ser que se diga lo contrario, todos los textos que se citan textualmente fueron traducidos del inglés por el autor de este artículo. 
6) La herida que el recurso a la violencia deja en el victimario mismo, pues el mal que realizó afecta su propio ser y su propia alma (pp. 31-41).

La implementación de una estrategia de reconciliación debe hacer frente a las distintas heridas que deja la injusticia política de un conflicto, de tal manera que pueda contribuir a la sanación de las mismas y a la reconstrucción del tejido social que ha sido destruido por la violencia.

\section{Razón 3}

Porque la reconciliación nos permite hacer frente a las tensiones, conflictos y heridas que surgen entre desplazados internos, migrantes forzados y refugiados, y las comunidades, en los lugares de origen, tránsito y llegada (Schreiter, 2014, pp. 107-113).

El proceso de desplazamiento y migración implica:

- Vivir una ruptura con la familia y con todo aquello que es familiar y se ha tejido socialmente en las comunidades de origen.

- Afrontar los riesgos y peligros del proceso de desplazamiento y la interacción, algunas veces conflictiva, con las comunidades que están en el tránsito.

- Asumir la alienación y los retos que implica llegar a una nueva realidad, experimentada como “tierra extranjera”, y superar las tensiones y ambigüedades que surgen dentro de las comunidades de acogida.

\section{Razón 4}

Porque las circunstancias, tras los acuerdos de paz o desmovilizaciones de grupos armados, obligan a la convivencia de los distintos actores sociales (víctimas, victimarios, testigos mudos de la violencia, funcionarios públicos, etc.), después de un conflicto prolongado y degradado; así, cuanto más positivo sea este convivir, más viable será la construcción 
de un futuro compartido (Lederach, 1998, p. 63). La reconciliación, ciertamente, puede contribuir a ello. Estamos abocados no solo a coexistir, sino también a construir un proyecto político compartido, un proyecto de sociedad, en la que todos tengamos lugar y nuestros derechos sean reconocidos.

Porque la reconciliación es una forma de ajustar cuentas con un pasado doloroso y poder proyectar un horizonte de futuro compartido entre actores, cuyo tejido social ha sido roto por el conflicto o la represión. Para Bloomfield (2006), este es el modo de avanzar hacia otras formas de convivencia y cohesión social, que garanticen los niveles requeridos de verdad y justicia (pp. 11-14).

Sin un proceso de reconciliación encaminado a construir o reconstruir relaciones, será difícil que una sociedad funcione de alguna manera significativa, y mucho menos que funcione para construir paz sostenible y un cambio permanente. La reconciliación no es un estado paradisíaco de paz y amor en el que todos son uno. Es un proceso incómodo y difícil en el que los antiguos enemigos encuentran formas dolorosas de empezar a cooperar en aras de un mejor futuro (p. 47).

\section{Razón 5}

Porque la reconciliación permite hacer frente al riesgo de seguir reproduciendo el ciclo de la víctima (como indica la figura 3), con su llamado vengarse del victimario, y el ciclo del agresor (como indica la figura 4), que ve al otro como enemigo y a la violencia como salvadora, lo cual inhibe la apertura hacia un horizonte político compartido.

Por una parte, la reconciliación puede generar dinámicas que les permitan a las víctimas salir del ciclo de victimización en el que están insertas y, así, hacer el tránsito de víctimas a ciudadanos empoderados y sujetos de su propio proyecto de vida. Por otra parte, la reconciliación también puede ayudar a romper con la continuidad del ciclo del agresor y evitar, de esta forma, la repetición de los procesos de victimización. 
26 Controversia 211

\section{Figura 3. El ciclo de la víctima}

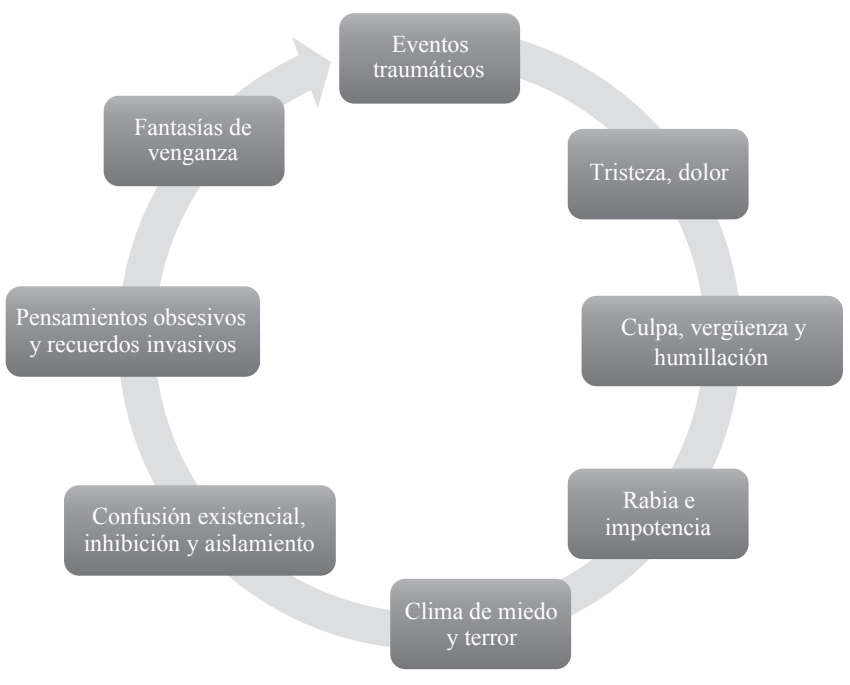

Fuente: Yoder (2005) y Villa (2014).

\section{Figura 4. Ciclo del agresor}

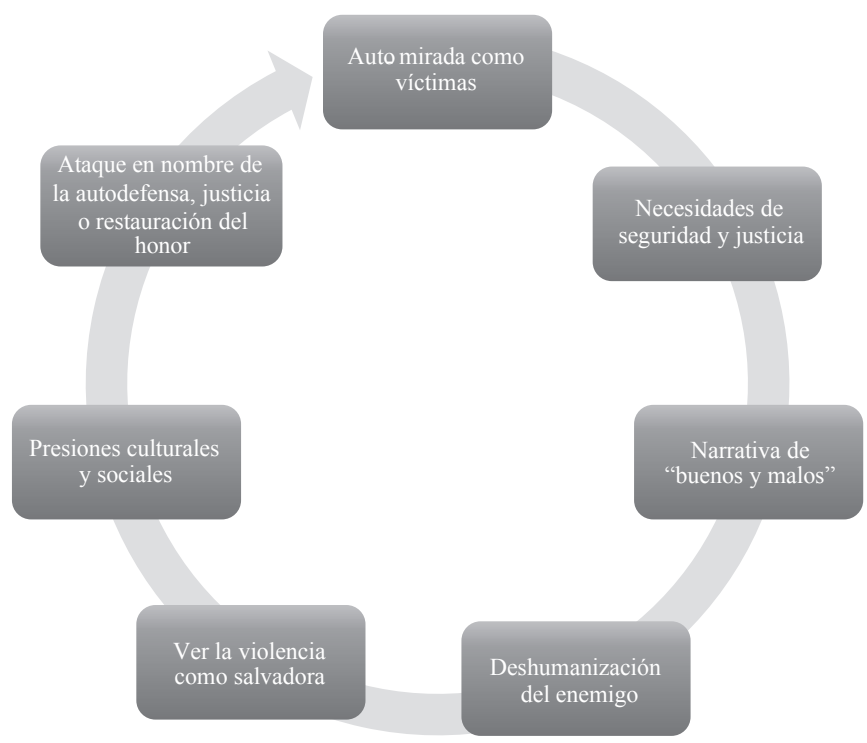

Fuente: Yoder (2005). 


\section{Razón 6}

Porque la reconciliación puede ayudar a avanzar en los procesos de construcción de paz, a través de una lógica territorial, que pueda hacer frente a las disparidades y exclusiones causadas o exacerbadas por la guerra como en el caso del despojo de tierras.

Es indiscutible que los ocho millones de hectáreas (aproximadamente), que fueron despojadas a los campesinos desplazados, plantean un reto grande en términos de esfuerzos de restitución de tierras (reparación) y de desarrollo rural con equidad y alternativas para la economía campesina. Aquellas zonas donde la dinámica del conflicto fue más fuerte coinciden en gran medida con las zonas donde la expropiación de tierras fue mayor. Los procesos de coexistencia de actores del conflicto en estas zonas plantean el reto de impulsar dinámicas de construcción de paz y reconciliación en lógica territorial, para hacer viable y sostenible una convivencia entre antiguos enemigos (de Roux, 2018, pp. 141-177).

\section{¿Qué concepción de reconciliación requiere un contexto como el colombiano?}

Un conflicto largo y degradado como el nuestro exige una aproximación compleja en términos de reconciliación para poder responder a las múltiples heridas que dejó la guerra y construir un horizonte compartido como sociedad. Existen múltiples visiones de la reconciliación, algunas de ellas opuestas y parciales. En relación con el contexto colombiano, es necesario ir más allá de comprensiones limitadas y sesgadas de la reconciliación, para alcanzar una visión integral y dinámica de la misma, que pueda responder adecuadamente a las distintas dimensiones, en las que se requiere sanar heridas y reconstruir el tejido social, tras sesenta años de confrontación. Con ese objetivo, vamos a dialogar sobre el tema, bajo algunas de las múltiples perspectivas que se han desarrollado, con base en diversos contextos conflictivos a nivel mundial, para lo cual, se hacen dos anotaciones introductorias: una sobre escuelas que han trabajado en el ajuste de cuentas con el pasado y otra sobre los 
niveles antropológicos y sociales en los que se desarrollan el conflicto y la reconciliación.

Para ubicar adecuadamente el debate, es importante rescatar las distintas escuelas temáticas que se han planteado el tema del ajuste de cuentas con un pasado difícil (violento y autoritario), las cuales se enfocan en la problemática a partir de diversos ángulos. Según Salter (2016), su desarrollo es relativamente reciente (de los años ochenta en adelante) y los aspectos que consideran se yuxtaponen en gran medida:

a) Justicia transicional: escuela que ha estado vinculada al desarrollo de las Comisiones de la Verdad y la Reconciliación y crecientemente asociada a respuestas legales y judiciales; es una perspectiva que reivindica como sus componentes principales la verdad, la justicia, la reparación y la no repetición.

b) Ajustando cuentas con el pasado (dealing with the past): una expresion englobante que abarca instrumentos como la justicia, el reconocimiento, la rendición de cuentas, la reparación, el fin de la impunidad y la garantía de no repetición. Prescinde de una perspectiva de reconciliación, porque consideran que no es adecuada en algunos contextos y porque estiman tiene una carga religiosa muy grande.

c) Reconciliación: escuela que está más asociada a un énfasis de reconstrucción de relaciones y para muchos implica la sanación, el perdón y la coexistencia; reivindica como sus componentes los procesos de contar la verdad, impulsar la justicia, promover la reparación y sanar las heridas que deja el conflicto. Se ha desarrollado tanto en ámbitos religiosos como seculares (p. 3).

El autor de este artículo opta por el uso de esta última perspectiva, pues considera que, en el contexto colombiano, para poder saldar cuentas con un pasado de más de cincuenta años de conflicto, se requiere de un horizonte, en el que se puedan sanar las heridas producidas y se abra camino hacia a los procesos de verdad, justicia y reparación. Esto es posible gracias a la reconciliación. 


\section{Tabla 1. Dimensiones del conflicto y la reconciliación ${ }^{3}$}

\section{Niveles de conflicto y enemistad}

Conflictos dentro de uno mismo
Niveles de acercamiento y reconciliación

Reconciliación con uno mismo (perspectiva antropológica)

Reconciliación con Dios y

Conflictos con Dios y/o la experiencia de sentido lo que hace sentido en $\mathrm{c} / \mathrm{u}$ (perspectiva teológica y existencial)
Conflictos intersubjetivos (en relaciones personales, familiares, comunitarias)

Conflictos sociopolíticos (violentos, por autoritarismo y disputa del Estado)

Conflictos (destrucción) con (d)el medio ambiente
Reconciliación intersubjetiva (perspectiva social y relacional)

Reconciliación sociopolítica (perspectiva política e institucional)

Reconciliación con la creación (perspectiva ecológica)

En razón a las aproximaciones que se hacen a este tema, es necesario tener en cuenta las diversas dimensiones en las que operan el conflicto y la reconciliación, pues, el hecho de que algunos autores consideren apenas una parte de ellas, puede generar confusiones, ya que abarcan tan solo una visión parcial de lo que realmente es la reconciliación. Así como hay niveles de conflicto y enemistad, también hay niveles de acercamiento y reconciliación. Es importante distinguir las diferentes dimensiones (personal, horizonte de sentido, relaciones interpersonales, dimensión sociopolítica y dimensión ecológica), pues ellas conllevan estrategias y dinámicas distintas en el proceso de impulsar la reconciliación.

3 Estos niveles son una reflexión personal, derivada de los niveles de reconciliación establecidos por la Compañía de Jesús en sus Congregaciones Generales 35 (2008) y 36 (2016), en los que se distingue un triple horizonte de reconciliación con Dios, con los otros (humanidad) y con la creación. 
En algunos contextos y conflictos, es necesario desarrollar procesos en varias de estas dimensiones. En Colombia, el foco ciertamente está a nivel de una reconciliación sociopolítica, sin embargo, en muchas situaciones, no se puede prescindir de la promoción de dinámicas de reconciliación personal y religiosa, de reconciliación interpersonal o de reconciliación con la creación.

Tras las anotaciones previas, a continuación, podemos revisar seis aproximaciones a la reconciliación (la mayoría de origen internacional), que pueden aportar al proceso de construcción de una paz durable y sostenible en Colombia. Algunas de estas perspectivas, de hecho, ya se están aplicando, en pro de enriquecer los esfuerzos de reconciliación que se vienen impulsando en el país. Sin lugar a dudas, un diálogo más a fondo con las experiencias de otros contextos conflictivos nos puede ayudar a integrar elementos valiosos, que den lugar a una estrategia de reconciliación, pertinente a nuestro propio contexto.

\section{1) La reconciliación entendida como un concepto englobante y realista de construcción de un futuro compartido sostenible}

Esta es una perspectiva que ha sido desarrollada y reivindicada por David Bloomfield (2006, 2015 y 2016), quien dirigía en su momento el Centro Berghof en Berlín. También aparece con claridad en el manual desarrollado en el 2003, por el Institute for Democracy and Electoral Asistance, en Estocolmo, Suecia, en el que Bloomfield también participó. Dichos estudios enfrentan a algunas de las siguientes paradojas en torno a la reconciliación:

- Se ha entendido la reconciliación desde una perspectiva maximalista: estado final armonioso y de perdón total. Antes bien, se requiere una definición más pragmática y minimalista: condiciones mínimas para la reconstrucción de una convivencia común entre los actores enfrentados. 
- Se ha entendido la reconciliación como perdón y olvido, por lo tanto, en tensión irreconciliable con verdad, justicia y reparación. Antes bien, se requiere una definición capaz de coordinar estos tres elementos en la misma dirección.

- Se ha entendido la reconciliación como una situación que les exige a las víctimas conceder el perdón a los victimarios. Antes bien, se requiere una definición que salve el derecho individual a no perdonar, que vea el perdón como discrecional de las víctimas en un proceso de reconstrucción de relaciones.

Lo que estos autores buscan es aproximarse a un concepto modesto de reconciliación, pero útil y funcional para la tarea de construir una paz durable y sostenible:

Reconciliación es el proceso de gradualmente (re)construir amplias relaciones sociales entre comunidades afectadas por una violencia sostenida y ampliamente extendida, de forma tal que puedan con el tiempo llegar a negociar las condiciones y compromisos que implica una realidad política compartida (Bloomfield, 2006, p. 12).

A saber, luego de un violento conflicto social, la reconciliación es el largo, amplio y profundo proceso de construir relaciones intercomunitarias, que incluye como componentes constitutivos la justicia, la verdad, la sanación y la reparación. En otras palabras, se debe usar la reconciliación como un término englobante (umbrella term) de distintas dimensiones (Bloomfield, 2015, pp. 16 y 17), que se orientan a la reconstrucción de relaciones y del tejido social, de forma que posibiliten la coexistencia positiva de antiguos enemigos. La reconciliación es, por lo tanto, un proceso de reconstrucción realista de relaciones, "reconstrucción de unas relaciones mínimas de trabajo - sociales, políticas, económicas, etc.—, que permitirán que una sociedad dividida dé los primeros pasos hacia un futuro compartido sostenible" (Bloomfield, 2006, p. 19). 
Esta perspectiva identifica como componentes principales de la reconciliación cuatro elementos o procesos, que hacen posible que el pasado sea puesto en el lugar adecuado para poder (re)construir una convivencia en común:

- Revelar la verdad de lo que pasó, lo cual pone en juego ejercicios de memoria para recordar y hacer visible el dolor y sufrimiento padecido.

- Acercarse a la justicia (ya sea retributiva o restaurativa), buscando las formas de justicia que permitan que la barbarie cometida no quede en la impunidad.

- Impulsar la reparación, para que las víctimas puedan recibir una compensación por las pérdidas que han sufrido; puede ser individual o colectiva.

- Sanación, curación de las heridas, en muchos casos pasando por la experiencia espiritual y por el perdón, para retejer los proyectos de vida personal y comunitarios (Huyse, 2003, pp. 23 y 24; Bloomfield, 2006, p. 12).

En la aproximación al debate sobre el tema, se pueden identificar otros componentes complementarios en esta tarea, que desarrollan y consolidan socialmente el proceso de reconciliación y responden a las dimensiones económica, política y cultural de la vida social:

- Un proceso de desarrollo, ya que lo anterior no podrá ser exitoso sin el sustento de un desarrollo económico que ofrezca acceso a los medios de vida a todos y todas, particularmente a las víctimas (Bloomfield, 2006, p. 12).

- Condiciones políticas de instituciones que funcionen y den seguridad, es decir, una institucionalidad que preste los servicios que 
requiere la población y garantice condiciones de seguridad para toda la población, particularmente en las zonas más conflictivas (Philpott, 2012, pp. 175-181).

- La consolidación de una cultura de paz, reconciliación y noviolencia, es decir, consolidar valores culturales que rompan con una cultura de violencia y afirmen la vida, la dignidad humana, la transformación no-violenta de conflictos, la honestidad y el respeto por la diferencia (Rigby, 2001, pp. 188-191).

\section{2) La reconciliación entendida como lugar de encuentro de los actores y energías de la confrontación}

Esta segunda aproximación a la reconciliación ha sido desarrollada por John Paul Lederach, reconocido norteamericano que ha trabajado en el campo de los estudios de paz y resolución de conflictos a nivel mundial. Su influjo en nuestro medio es grande y sus intuiciones han acompañado muchas de las intervenciones que se han hecho en reconciliación y construcción de paz en Colombia.

Como menonita, Lederach no oculta las raíces creyentes de su reflexión sobre la reconciliación como lugar de encuentro, que tiene el Salmo 85 como punto de partida: "La misericordia y la verdad se encuentran, la justicia y la paz se abrazan” (versículo 11). A su vez, el autor ha tomado lugar en el trabajo de mediación y en talleres de resolución de conflictos con comunidades que enfrentan divisiones significativas. De esta forma, advierte que estamos invitados a buscar que la reconciliación sea un espacio en el que nos podamos encontrar con nosotros mismos, con los otros y con Dios. Debemos ayudar a crear una dinámica social, en la cual, las energías e intereses sociales expresados por los conceptos de verdad, misericordia, justicia y paz puedan tener voz, encontrarse y resolver positivamente las paradojas que los definen. Las personas tienden a tomar estas cuatro energías como contradictorias, reivindicadas por distintos actores dentro del conflicto; asimismo, quienes 
abogan por verdad y justicia son tomados como adversarios de los que claman por misericordia y paz.

La reconciliación solo es posible cuando damos espacio a estos cuatro conceptos, cuando descubrimos el potencial reconciliador, en la medida en que asumimos estos cuatro dinamismos. Para Lederach (1998),

La reconciliación necesitará encontrar el modo de abordar el pasado sin quedarse encerrado en un círculo vicioso de mutua exclusividad inherente a ese pasado. Las personas necesitan la oportunidad y el espacio para expresar el trauma y el dolor provocados por lo que se ha perdido y la ira que acompaña al dolor y a las injusticias que han sufrido [...]. Es la posibilidad de crear un espacio social donde la verdad y el perdón estén validados y unidos, y no separados y fragmentados. La reconciliación ha de invitar a la búsqueda de un encuentro donde las personas puedan replantearse sus relaciones y compartir sus percepciones, sentimientos y experiencias, con el fin de crear nuevas percepciones y una nueva experiencia compartida (pp. 55 y 59).

Por ello, para el autor, la reconciliación tiene que ver con tres paradojas específicas:

[En primer lugar, en un sentido general], la reconciliación promueve un encuentro entre la expresión franca de un pasado doloroso y la búsqueda de la articulación de un futuro interdependiente a largo plazo.

[En segundo lugar], la reconciliación proporciona un punto de encuentro para la verdad y la misericordia, donde está ratificado y aceptado que se exponga lo que sucedió y se cede en favor de una relación renovada.

[En tercer lugar], reconoce además la necesidad de dar tiempo y espacio a la justicia y la paz, donde enmendar los daños va unido a la concepción de un futuro común (p. 59). 


\section{3) La reconciliación entendida con acciones diferenciadas según las fases del conflicto y de la construcción de paz}

Una tercera aproximación se ha llevado a cabo por Conciliation Resources en Londres, quienes han adelantado un largo trabajo de seguimiento a procesos de paz en muy distintos lugares del mundo, incluido Colombia. Ellos se han aproximado a la reconciliación, con base en los distintos contextos y el momento en el que se encuentran el conflicto y el proceso de paz.

En palabras de Salter (2016),

los procesos de reconciliación pueden ayudar a transformar las relaciones en las sociedades afectadas por el conflicto, alentar el ajuste de puntos de vista conflictivos y facilitar el espacio para que individuos y grupos se involucren en procesos políticos inclusivos. Para apoyar la inclusión, la reconciliación requiere enfoques integrados de reconciliación desde arriba hacia abajo y de abajo hacia arriba, que involucren tanto a las élites como a las no-élites, y sensibilidad a los tipos de actividades de reconciliación apropiadas a las diferentes circunstancias y fases de los procesos de paz (p. 1).

En consecuencia, en el Accord Insight $n .^{\circ} 3$, analizan ejemplos de promoción de la reconciliación, de acuerdo a las fases del conflicto y el proceso de paz:

Caso de Georgia/Abjacia (Abkhazia) antes de un acuerdo de paz, es decir, cuando el conflicto todavía continúa: en este contexto ha sido clave encontrar formas de conexión con el pasado para que la gente pueda llegar al momento en que vean el acuerdo político posible.

Caso de Colombia con las negociaciones con las FARC, es decir, durante las negociaciones hasta alcanzar un acuerdo de paz: trabajar por la reconciliación no es solo cuestión de justicia transicional y de perdón, sino que también supone la reconstrucción de confianza del Estado con la sociedad y la necesidad que todos los actores reconozcan la verdad de los abusos cometidos. 
El caso de Mindanao (Filipinas) con la insurgencia musulmana, es decir, en una fase posacuerdo, cuando se está implementando el acuerdo de paz: dado que hay muy distintas visiones de lo que reconciliación y sanación significan, es importante contar con una estrategia de comunicación y con mecanismos para involucrar a la población local en el proceso de implementación de los acuerdos de paz.

El caso de Irlanda del Norte en una fase posacuerdo, cuando se está consolidando el acuerdo de paz: dada que la prioridad del acuerdo de paz fue compartir el poder más que construir un futuro compartido, queda el reto de ajustar cuentas con el pasado (contar la verdad como compromiso de todos) y de encontrar el consenso mínimo necesario sobre cómo la gente puede vivir junta sin volver a la violencia (Salter y Yousuf, 2016, pp. 16-44).

La reconciliación y la construcción de paz requieren de este diálogo con el momento del conflicto y del proceso de paz, para que las estrategias que se desplieguen respondan a los retos que cada momento plantea. Esto sigue siendo válido hoy en Colombia, donde los avances en una apuesta hacia la reconciliación dependen del momento del conflicto (una violencia que no termina y sigue conectada con dinámicas de las economías ilegales y con el incremento importante de las infracciones al DIH) y del momento del proceso de paz (las dificultades en la implementación del acuerdo de paz con las FARC y un proceso de paz con el ELN que no avanza con claridad).

\section{4) La reconciliación entendida como el paso de la confrontación armada a la competencia política no-violenta}

Esta cuarta perspectiva se ha desarrollado en el contexto colombiano, en el ámbito de la reflexión y la lucha por la defensa de los derechos humanos. Para Orozco (2005), "la guerra colombiana, sobre todo en cuanto confrontación no reglada y altamente degradada entre guerrillas y paramilitares, constituye un espacio ampliamente habitado, si 
no gobernado, por el odio vindicativo y la rabia retaliatoria” (p. 234). Esta ha sido una guerra irregular, que apareció en el imaginario de los actores, enfrentados como en un juego de espejos, entre enemigos que se representan al mismo tiempo como víctimas y como vengadores. Tanto guerrillas como paramilitares, al igual que algunos preclaros representantes del Estado, vivieron este juego de espejos en sus acciones y representaciones del conflicto.

Por tanto, para el autor,

la reconciliación, entendida en sentido realista, ajeno a las fantasías consensualistas, consiste en el acercamiento progresivo de las narrativas opuestas. Acercar las narrativas opuestas, por su parte, es escapar al blanco y negro de la dialéctica simple y asimétrica del victimario y de la víctima y adentrarse en la verdad más profunda y opaca de los grises, es reconocer la presencia y la significación de las zonas grises, de figuras que son a la vez víctimas y victimarios, simultáneamente culpables e inocentes (p. 256).

Esta perspectiva de reconciliación nos remite al proceso de configuración del Estado y lo que eso conlleva en términos de control de la violencia y la venganza:

El Estado moderno, con su monopolio legítimo y eficaz de la violencia, [...] es antes que nada negación y superación de la guerra civil. Su surgimiento [...] podría ser interpretado como la expresión de un largo proceso de domesticación y transformación de la venganza (p. 236).

En ese horizonte de consolidación del Estado, según Orozco, la reconciliación se traduce políticamente en un arreglo institucional en el que los "antiguos enemigos militares se transforman en competidores políticos" (p. 10), con un reconocimiento mutuo entre las partes y dentro de un marco de confrontación democrática. 


\section{5) La reconciliación entendida como ruptura de los ciclos de la víctima y el victimario}

Esta es una perspectiva que ha sido desarrollada en el ámbito de la Eastern Mennonite University, en los EE. UU., por Carolyn Yoder (2005), que deriva en una perspectiva más psicosocial de aproximación a los efectos negativos de los conflictos armados en la población y la manera de superarlos. Dado que existe el riesgo de que víctimas y agresores queden atrapados en ciclos de victimización y agresión, se requiere promover procesos que permitan romper con dichos ciclos y avanzar hacia posibilidades de reconciliación, como lo indica la figura 5 .

\section{Figura 5. Ruptura del ciclo de la víctima}

\section{RECONEXION}

+ Negociar soluciones y ubicar el trauma en un nuevo horizonte

+ Buscar justicia creativamente

+ Asumir el camino de perdonar

+ Comprometerse con el ofensor y la sociedad

+ Asumir un horizonte de tolerancia y coexistencia

+ Reconocer la interdependencia y tomar riesgos en la relación

\section{RECONOCIMIENTO}

* Reconocer que el "otro" tiene historia

* Reconocer el propio sufrimiento, hacer el duelo de las pérdidas y nombrar los miedos

\section{SEGURIDAD}

- Encontrar seguridad que permite liberarse de ciclo de trauma y poder iniciar un camino de sanación
Posibilidad de reconciliación

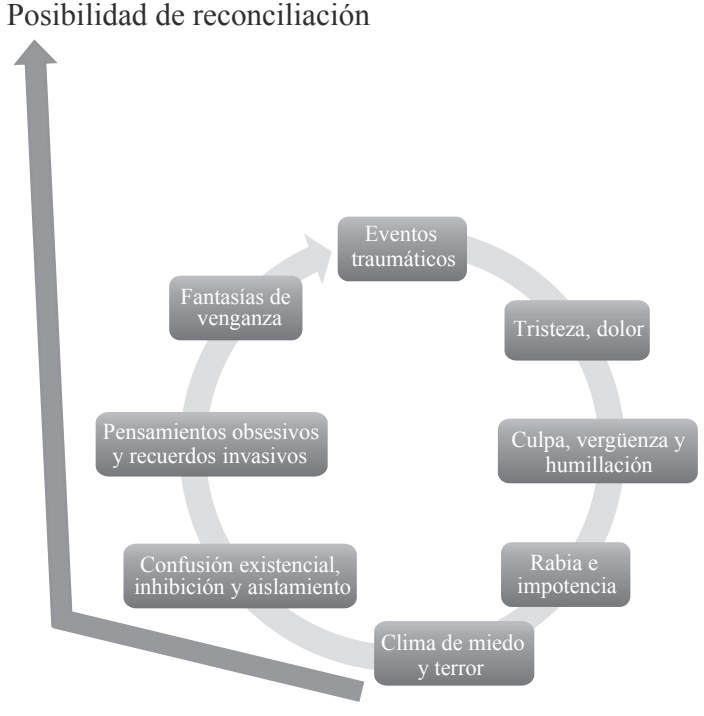

Fuente: Yoder, 2005: párr. 668. 
Esto demanda unas condiciones mínimas de seguridad, que permitan que los afectados puedan romper el ciclo en el que están "atrapados" y avanzar hacia dinámicas de reconocimiento y reconexión, en las que asuman positivamente el trauma generado por el conflicto y se reconecten con la sociedad como agentes activos de los procesos sociales.

\section{6) La reconciliación entendida como sanación y redefinición del lugar de la víctima en la sociedad}

La sexta y última perspectiva de reconciliación que vamos a presentar ha sido desarrollada por Robert Schreiter en Notre Dame University, en los EE. UU. Esta parte de una visión cristiana de reconciliación con migrantes y refugiados, muchos de ellos víctimas de la violencia, y conecta con la última perspectiva mencionada. Para Schreiter (2008), en esta propuesta, la comprensión de la reconciliación se basa en los siguientes puntos:

1) Dios es agente de la reconciliación y los creyentes embajadores de dicha reconciliación: "Todo proviene de Dios que nos reconcilió consigo por Cristo y nos confió el ministerio de la reconciliación” (2 Cor. 5,18);

2) la sanación que implica la reconciliación comienza con la víctima, reconociendo el trauma sufrido;

3) esta sanación lleva a la víctima a un nuevo lugar (nueva creación), que realinea las asimetrías y le permite volver a ganar protagonismo y autonomía (agency);

4) la historia de la victimización y el desplazamiento tiene que ser redefinida (reframed) para colocar la narrativa de los hechos sufridos y el dolor padecido en una nueva perspectiva y sentido;

5) el proceso de sanación nunca es completo y esto no se puede olvidar (pp. 114-116). 
Este modelo está orientado a buscar la justicia, pues conlleva el reconocimiento del trauma sufrido, para lo cual establece la verdad de lo vivido y sana la memoria de lo sufrido (pp. 122-126). Además, promueve la realineación de las asimetrías en las que queda inmersa la víctima, el migrante y refugiado, con el objetivo de que ellos puedan reganar protagonismo y autonomía (agency). Es decir, si las víctimas no son agentes sociales que puedan volver a asumir su proyecto de vida en sus propias manos, difícilmente podemos decir que se ha avanzado hacia su reconciliación.

\section{¿Quiénes están involucrados en la reconciliación?}

En un conflicto como el colombiano, con un nivel de víctimas que puede llegar al $17 \%$ de la población y con diversos actores armados, los sujetos y agentes que deberían estar involucrados en la reconciliación abarcan prácticamente a toda la sociedad. En otras palabras, un conflicto que ha afectado en mayor o menor medida a toda la sociedad, solo puede superarse si se genera un proceso hondo, que no solo permita la coexistencia entre todos, sino que también garantice la sanación de las heridas y la reconstrucción del tejido social roto por la guerra; de esta manera, se puede consolidar un proyecto político compartido para todos en la sociedad.

En este punto es importante tener presentes los principales actores involucrados en este proceso de reconciliación:

- En primer lugar, y, ante todo, tenemos las víctimas del conflicto, aun los desplazados internos y refugiados. Son los que han sufrido de manera directa los impactos de la guerra, que ha afectado no solo a las personas, sino también a las comunidades y a sus familias, incluidos los hijos y nietos (que se ven afectados por el trauma de la violencia y el desplazamiento). Sin su participación en los procesos de sanación y justicia transicional, no es posible consolidar dinámicas de reconciliación. Las víctimas tienen que abrirse a la reconciliación, sin esperar que los victimarios lo hagan, para 
poder avanzar en la curación de sus heridas; así, pueden volver a ganar protagonismo y autonomía como ciudadanos y ser actores de sus propios proyectos de vida.

- Como segundo actor de la reconciliación, encontramos aquellos que tienen directa relación con las víctimas y, en ese sentido, han recibido un impacto indirecto de los procesos de victimización que se desarrollaron durante el conflicto armado. Entre ellos, están las comunidades que acogen e integran a las víctimas y desplazados por la violencia, así como también las organizaciones humanitarias, sociales y eclesiales que les prestan algún servicio. Dada su cercanía con las víctimas, que en muchos casos se traduce en afectación, ellos son un actor importante en los procesos de reconstrucción de relaciones y restablecimiento de confianza y credibilidad en los procesos sociales y políticos con la participación de todos los involucrados.

- Un tercer actor es la sociedad en general, cuyos miembros han sido testigos mudos de la barbarie del conflicto armado y en muchos casos mostraron desinterés o desconocimiento de la realidad de las víctimas. Esta ha sido una sociedad imbuida por una "cultura de violencia y venganza", que requiere participar en procesos sociales para poder establecer en la sociedad una cultura de paz y reconciliación, que propenda por la vida y por la no-violencia y consolide la práctica de la sinceridad, la verdad, la justicia y el perdón (Rigby, 2001, pp. 183ss).

- Un cuarto actor es la institucionalidad pública y estatal, que juega un rol tanto en la dinámica del conflicto como en el proceso de reconciliación. En relación con su rol en el conflicto, la institucionalidad pública no garantizó y protegió suficientemente los derechos de las víctimas, como constitucionalmente debió hacerlo; es más, hay funcionarios públicos directamente involucrados en los abusos, particularmente, miembros de la fuerza pública. De ahí la importancia del compromiso de la institucionalidad pública en la reconciliación. El Gobierno debe liderar la búsqueda de una solución al conflicto, prioritariamente de un acuerdo de paz que ponga fin a la barbarie; 
así mismo, debe acompañar y financiar en gran medida las políticas públicas que velen por un proceso de reconciliación como la búsqueda de la verdad, la aplicación de justicia, la reparación de las víctimas y la sanación de las múltiples heridas en toda la sociedad. Si no existe una clara opción por parte del Gobierno y la institucionalidad pública en torno a la reconciliación, es difícil avanzar por este sendero.

- Como quinto actor, encontramos a los responsables de la barbarie y victimización del conflicto, es decir, a todos los actores armados (guerrillas, paramilitares y grupos posdesmovilización, fuerza pública). Obviamente, estos deberían ser actores importantes en la reconciliación, a través del reconocimiento de la verdad de los abusos cometidos, del sometimiento a la justicia y de la disposición para reparar a las víctimas y no repetir los abusos realizados. Sin embargo, no siempre los victimarios manifiestan una disposición real para participar en un proceso de reconciliación. En palabras de Todorov, "los victimarios quieren olvidar, en tanto que las víctimas no pueden olvidar. Por ello, las víctimas tienen derecho a olvidar, en tanto que los victimarios tienen la obligación de recordar" (Orozco, 2005 , p. 252). Las políticas de justicia transicional deben garantizar que cualquier medida de clemencia para los victimarios vaya acompañada de una obligación de revelar la verdad y de aceptar la responsabilidad en los abusos cometidos. Para Lederach (2008), "la reconciliación no es perdonar y olvidar, sino 'recordar y cambiar'” (p. 228), a saber, memoria y transformación a partir de medidas de perdón.

- Por último, un actor importante es la comunidad internacional, que ciertamente juega un rol en los procesos de reconciliación. Por una parte, está todo el respaldo político otorgado a la búsqueda de alternativas al conflicto, por ejemplo, el apoyo de las Naciones Unidas a los acuerdos de paz y su implementación en distintos contextos conflictivos, incluso en Colombia. Por otra parte, está el rol que puede jugar en el apoyo y financiamiento de un proceso sostenido 
de construcción de paz y reconciliación, el cual, puede tomar un largo tiempo.

\section{¿Cómo gestar la reconciliación? Distintos caminos para promoverla}

En este punto, fijamos la mirada en los distintos caminos y modelos pertinentes para avanzar hacia la reconciliación. Entre muchos que podríamos mencionar, queremos llevar la atención sobre cinco elementos, importantes como caminos para alcanzarla, en un contexto como el colombiano.

En cuanto al cómo de la reconciliación, para Bloomfield (2006), un primer elemento tiene que ver con la necesidad de un proceso, que consiste en una doble aproximación, que deben practicar los actores de la reconciliación:

- Se requiere una aproximación de arriba hacia abajo (top-down), de carácter más político y realista. Es promover lo que se necesita para construir confianza cívica, alcanzar reconciliación política y reciprocidad democrática, construir adecuadas relaciones de trabajo y coexistencia. Está relacionada con los acuerdos de paz y la definición de políticas públicas que logren implementarse a nivel de toda la sociedad en relación con el Estado.

- Igualmente es necesaria una aproximación de abajo hacia arriba (bottom-up), una aproximación de carácter más cultural y que busca la reconciliación interpersonal; implica la interacción personal entre los previos enemigos y un compromiso subjetivo entre las partes. Son los procesos que se impulsan a nivel local y comunitario, a nivel organizativo y que escalan la dinámica social (pp. 25-28).

Dichas aproximaciones son necesarias, como se ha podido constatar en el caso colombiano. No basta un acuerdo de paz y la implementación del mismo desde la política gubernamental y desde los grupos desmovilizados; 
también son necesarios los procesos que ayuden a construir la convivencia y coexistencia entre los actores antes enfrentados a nivel de los territorios. Hay regiones en las que coexisten actores desmovilizados de los distintos grupos, que fueron responsables de la victimización de la población, también hay víctimas de los distintos actores armados y hay institucionalidad pública y población que ha sido testigo mudo de los abusos cometidos. Por lo tanto, es necesario promover la convivencia entre todos y volver a tejer los lazos sociales mínimos de confianza y credibilidad, para poder alcanzar los niveles mínimos requeridos de reciprocidad democrática.

Para continuar en el nivel del "cómo", un segundo elemento importante es el reconocimiento de que no existe un solo modelo de reconciliación, sino varios. En una reflexión sobre la reconciliación, gestada en el marco del Servicio Jesuita a Refugiados, Stephen Pope (2013) mostró la existencia de cinco modelos de reconciliación como algo que "puede ayudarnos a identificar los límites distintivos, las oportunidades y las necesidades encontradas en entornos problemáticos":

Modelo 1: la reconciliación como adopción de una actitud de "perdonar y olvidar" 4 .

Modelo 2: la reconciliación es concebida como un estado de convivencia promovido, a través de la justicia retributiva.

Modelo 3: la reconciliación como la unificación nacional, a través de la verdad.

4 Este modelo no parecería conducir plenamente a la reconciliación. El modelo de perdón y olvido, que fue el que se aplicó en la España posfranquista bajo la figura de la amnistía y la amnesia (Rigby, 2001, pp. 39-60), no llevó al puerto final de la reconciliación, como ha podido verse en los reclamos de las familias de las víctimas hasta el día de hoy. Más bien, parece que lo que se requiere es "recordar y cambiar" (Lederach, 2008, p. 228), tal y como se expresa en las distintas formas de memoria y búsqueda de la verdad, que se han reivindicado desde las comunidades y organizaciones de víctimas como una forma necesaria de saldar cuentas con un pasado doloroso. 
Modelo 4: la reconciliación como construcción de la comunidad basada en el diálogo personal.

Modelo 5: la reconciliación como cohesión social reconstituida mediante la promoción del desarrollo socioeconómico (pp. 83-85).

La identificación que hace Pope de estos modelos se basa en el reconocimiento de un elemento fundamental de la reconciliación como aquello que configura el modelo; no obstante, si tenemos presentes otros componentes de la misma, podría haber otros más, como lo sugerimos a continuación:

Modelo 6: la reconciliación como reparación de las víctimas.

Modelo 7: la reconciliación como sanación de las heridas.

Modelo 8: la reconciliación como contar con instituciones que operen y garanticen seguridad.

Modelo 9: la reconciliación como construcción de una cultura de paz y no violencia.

Modelo 10: una combinación de componentes de los modelos anteriores.

Pero, en la práctica, difícilmente se encuentran estos modelos "en estado puro". Lo que podemos encontrar en muchas experiencias es una combinación de los distintos modelos mencionados, como puede verse en el caso colombiano, en los acuerdos de paz negociados con las FARC.

En tercer lugar, no hay una única forma de implementación de la justicia transicional. De hecho, se pueden distinguir distintas políticas tanto de memoria y verdad como de justicia y de perdón, como se puede observar en la figura 6 . En contextos de conflictos violentos, una parte 
importante del cómo de la reconciliación tiene que ver, ciertamente, con la manera en que se implementa un esquema o modelo de justicia transicional.

Figura 6. Modelos de justicia transicional

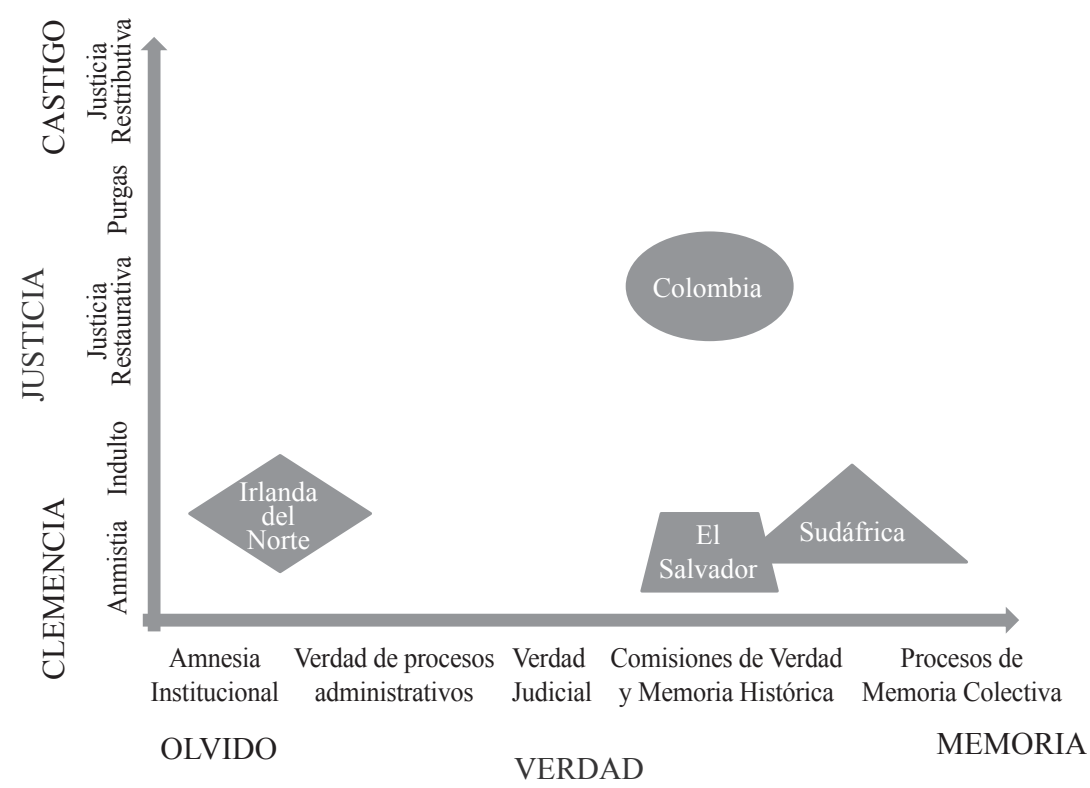

En el eje de la verdad, podemos encontrar formas de verdad que van desde el olvido promovido social e institucionalmente hasta los esfuerzos por recuperar la memoria más honda posible de la barbarie y los hechos victimizantes. Un primer nivel de políticas de verdad se ubica en la perspectiva del olvido; aquí están las iniciativas oficiales que han impulsado la amnesia institucional de los abusos cometidos, como en el caso de España, tras la dictadura de Franco (Rigby, 2001, pp. 39-61) o lo que se quiso hacer con las leyes de punto final en el momento del tránsito de las dictaduras a las democracias en Argentina y Chile (Orozco, 2005, pp. 182-206). 
Un segundo nivel de políticas de verdad tiene que ver con la exploración de la verdad que se alcanza en los procesos judiciales y administrativos. Según la estructuración del sistema judicial y de la operatividad de los mecanismos de investigación (fiscalía), es posible que los procesos judiciales y las sentencias que se producen alcancen un mayor o menor nivel de verdad, sin que esta llegue a ser completa. Por otro lado, en los procesos administrativos no siempre existen todas las condiciones para que el acercamiento a la verdad sea claro e imparcial, dado que algunos de estos procesos pueden estar influenciados por posiciones políticas de las instancias que los implementan; las purgas y depuraciones a que dan lugar pueden tener carga ideológica o política.

Un tercer nivel de políticas de verdad se puede encontrar en los procesos de esclarecimiento histórico, en los cuales, según el mecanismo utilizado, el nivel de verdad puede ser mayor o menor. A este nivel, el trabajo puede estar orientado al esclarecimiento de hechos concretos; así, depende de los niveles de acceso a la información (por ejemplo, si hay acceso a archivos secretos de instituciones estatales y fuerzas de seguridad), se puede alcanzar una aproximación grande a la verdad, aun cuando esta sea limitada en lo que respecta a hechos puntuales.

Aquí se encuentran los distintos tipos de comisiones de esclarecimiento histórico: comisiones de memoria histórica (como la establecida durante la administración Uribe en el caso colombiano), comisiones de la verdad (como la establecida en diversos países como en Sudáfrica y ahora en Colombia) y comisiones que promuevan procesos comunitarios de esclarecimiento de la verdad (como el Proyecto Interdiocesano de recuperación de la memoria histórica [REMHI] en Guatemala). Normalmente, el nivel de verdad es mayor cuando se da una dinámica colaborativa entre los procesos institucionales y la participación de instancias de la sociedad civil y organizaciones de derechos humanos.

En el eje de la justicia, las opciones oscilan entre la clemencia que lleva al perdón y el castigo de los culpables de los abusos. Un primer 
nivel de justicia — para algunos, "encubrimiento de impunidad" - tiene relación con las formas de perdón y clemencia que se pueden dar en los procesos de justicia transicional. Esta puede ser una amnistía sin condiciones, que, en muchos casos, es más un perdón recíproco entre vengadores; también puede ser una amnistía a cambio de verdad, como lo fue en Sudáfrica; y, por último, pueden ser formas de indulto de los culpables de los abusos.

Un segundo nivel en el eje de justicia tiene que ver con las formas de administrar justicia en los procesos de transición, que pueden ir de una justicia restaurativa a una justicia retributiva, y pasar por los procesos administrativos, que generan purgas y depuraciones de funcionarios públicos responsables de abusos. La justicia restaurativa busca, precisamente, restaurar las relaciones sociales quebradas por la violencia y por eso apela a sanciones de carácter restaurativo y reparador. La justicia retributiva sigue el principio clásico de que el culpable debe pagar por el daño que ha hecho a la sociedad y que ello debe expresarse a través de una pena efectiva de supresión de la libertad.

En el caso colombiano, el acuerdo de paz negociado con las FARC supone un modelo de justicia transicional que combina una apuesta por la justicia restaurativa y una por la búsqueda de la verdad, a través de una comisión de esclarecimiento de la verdad y una comisión de búsqueda de personas desaparecidas. En ese sentido, pensamos que se ha encontrado un modelo que logra ir más lejos que el de Irlanda del Norte, El Salvador y Sudáfrica en el proceso de ajuste de cuentas con el pasado violento que afrontaron estas sociedades.

Un cuarto aspecto en torno a cómo avanzar en la reconciliación se puede plantear a partir de las cualidades que debe tener el agente de reconciliación y la manera en que debe conectarse con la resiliencia de las comunidades afectadas por la violencia. 
Lederach (2002) resalta cinco cualidades que deben definir las prácticas de aquellos que realmente buscan respaldar los procesos de reconciliación (pp. 193-203): estas se centran en las reconstrucción de relaciones; implican un profundo proceso de acompañamiento, particularmente de las víctimas; suponen una dosis grande de humildad para entender los propios límites y poder reconocer sin ambages la verdad de la barbarie; buscan la restauración del tejido social de la comunidad; y, finalmente, conllevan el aprendizaje de "deambular en el desierto", no solo como preparación personal y comunitaria para la reconciliación, sino también porque "necesitamos desarrollar una mirada y unos compromisos de largo plazo, tanto programáticos como institucionales, por parte de aquellos que deseamos acompañar y apoyar la reconciliación” (p. 202).

Es importante mirar otro aspecto fundamental en el cómo de la reconciliación. Junto a su hija Angela, Lederach da un paso más para poder comprender los retos que plantean las búsquedas de reconciliación en los procesos sociales. La reconciliación y sanación social se entienden mejor como resiliencia y resistencia social (Lederach y Lederach, 2010, pp. 57-68). Desde una comprensión auditiva del cambio y el movimiento, esto supone tres submetáforas: la metáfora de lugar (como figura de la localización de uno mismo en el mundo), la metáfora de seguridad (como figura del sentirse en casa, en su hogar) y la metáfora de la voz (como figura de estar lo suficientemente cerca para ser oído).

Este es uno de los retos que enfrentan quienes acompañan a las víctimas en el tránsito de la violencia a una nueva convivencia: ayudarles a encontrar su propio lugar, donde se sepan seguros y puedan constatar que su voz es oída y reconocida. Por ello, "la reconciliación surge cuando la mezcla de voces encuentra su frecuencia natural [...], la reconciliación como sonido sugiere la necesidad de constante cuidado, compromiso

5 En alusión a la metáfora bíblica del pueblo judío, que deambuló cuarenta años en el desierto antes de llegar a la tierra prometida. 
circular, mezcla y remezcla de voces y la repetida profundización de conversaciones significativas” (pp. 205 y 206). Por eso,

la sanación social representa la capacidad de las comunidades y sus respectivos individuos para sobrevivir, localizar su voz y con flexibilidad innovar los espacios de interacción que nutren las conversaciones significativas y las acciones decididas en medio y después de una creciente violencia estructural (p. 208)

La sanación y la reconciliación implican un riesgo de vulnerabilidad que se basa en la "frágil voz del amor", que hace presencia en estos procesos (pp. 230 y 234). Desde la perspectiva de la resiliencia como metáfora de la sanación y la reconciliación, en múltiples experiencias de acompañamiento a víctimas, es posible identificar algunos aspectos claves de los procesos personales y comunitarios:

a) Opción preferencial por la comunidad local, es decir, reconocer la sanación social como un proceso principalmente basado en la comunidad.

b) La sanación social se focaliza en la resiliencia colectiva, es decir, en la capacidad de las comunidades de encontrarse ellas mismas respondiendo constructivamente a los retos de la violencia.

c) La resiliencia colectiva requiere la búsqueda de voz (voces) que permitan incorporar proactivamente la memoria y esperanza como imágenes vibrantes del futuro deseado ${ }^{6}$.

d) La voz se construye desde conversaciones llenas de sentido que surgen en el descubrimiento del nombrar, la demanda de una nueva pertenencia y el enmarcamiento de acciones con un claro propósito que crean eco social.

6 En nuestro contexto, esto se refleja en la metáfora de la defensa y promoción de la "vida querida" como aliciente de la búsqueda de alternativas comunitarias en medio del conflicto, tal y como se planteó en el Magdalena Medio, en el Programa de Desarrollo y Paz del Magdalena Medio (de Roux, 2018, p. 84). 
e) El eco social tiene el poder de tocar e impactar tanto la sanación individual al nivel micro como el más amplio contexto de reconciliación al nivel macro (pp. 208-215).

Un quinto elemento en torno al cómo de la reconciliación se puede plantear desde el ámbito religioso. En un contexto como el colombiano, la experiencia religiosa de muchas personas puede ser un factor efectivo para promover la reconciliación. Sin desconocer la "ambivalencia de lo sagrado" (Appleby, 2000), que puede incentivar dinámicas de violencia y exclusión, también es necesario estimar el importante papel que juegan las distintas religiones en la construcción de paz y reconciliación, como en el caso de Colombia (García Durán, 2006 y 2017, pp. 28-30).

Obviamente, la experiencia religiosa nos remite a una dimensión personal. Como bien lo plantea Alejandro Angulo (2015), los conflictos y la paz son un problema de relaciones humanas y las relaciones humanas son un problema de emocionalidad, que oscila entre el amor y el odio (pp. 47-53). Si queremos construir paz y promover reconciliación, es decir, mantener la emocionalidad del lado del amor, no tenemos otra alternativa que recurrir a la capacidad del ser humano de transformar sus odios en amores: esto se logra a través de la espiritualidad. Las heridas causadas por los sentimientos y las dinámicas sociales destructoras solo se sanan gracias a la reconciliación: "Solamente la espiritualidad puede prevenir y evitar la venganza” (p. 52). Es por eso que, desde la experiencia de sentido de cada uno, se deben potenciar las capacidades para la convivencia pacífica, la reconciliación y el perdón.

La experiencia religiosa no es solo un fenómeno individual, sino que también estima una dimensión colectiva de encuentro eclesial de los creyentes. Las iglesias necesitan seres reconciliados con Dios y con ellos mismos, que puedan ser agentes (ministros) de la reconciliación con otros, tal y como lo plantea Pablo en su segunda carta a los Corintios (Capítulo 5, 18-20). Pero, las iglesias también necesitan una dinámica colectiva que les permita ser agentes efectivos de reconciliación en plural. A saber, en 
la medida en que las iglesias puedan ser comunidades de reconciliación, tendrán más capacidad de trabajo por la paz y la concordia.

Y, ¿qué son comunidades de reconciliación? Para Schreiter (2000), ellas son:

- Comunidades seguras y protectoras, es decir, espacios de seguridad donde las víctimas pueden examinar y explorar sus heridas sin peligro y sin volver a ser victimizadas.

- Comunidades de memoria, es decir, donde las víctimas pueden recobrar una memoria que libera del sufrimiento pasado y abre las puertas para mirar el futuro sin la carga paralizante de la victimización vivida.

- Comunidades de esperanza, es decir, donde las víctimas pueden volver a soñar con un futuro mejor y más justo, con una convivencia donde el peso de los abusos sufridos ha quedado atrás y se cuenta con un proyecto de vida lleno de sentido y dignidad (pp. 133-134).

\section{¿Cuándo es necesaria la reconciliación? Sus tiempos y momentos}

En relación con el cuándo de la reconciliación, es decir, sus tiempos y momentos, es necesario resaltar al menos cuatro puntos.

En primer lugar, la reconciliación y la construcción de paz implican una dimensión de temporalidad, ya que siempre hacen referencia a una conjugación de energías que nos remiten al pasado, el presente y el futuro de una sociedad. En palabras de Lederach (2003), los componentes de la reconciliación (verdad, justicia, paz y misericordia) se despliegan en una línea de tiempo que va del pasado al presente y de ahí al futuro, a la posibilidad de un futuro compartido entre las partes enfrentadas:

La verdad, en la medida en que hace referencia a relaciones rotas por la violencia y el conflicto, a menudo se enfoca en el pasado buscando hacer claridad sobre lo que sucedió, establecer la responsabilidad por dicha 
ruptura, y definir qué y cómo se lo recordará. La justicia aborda una preocupación en el presente sobre cómo se tratará y se corregirá la ruptura [del tejido social] y la injusticia con alguna forma de rendición de cuentas. La misericordia y la esperanza [paz] levantan el horizonte de futuro y de restauración de la relación (pp. 262).

En segundo lugar, la construcción de paz y reconciliación es un proceso social a mediano y largo plazo, entonces, es un proceso que toma tiempo. Para Rigby (2001), sanar las heridas del pasado es "un proceso multidimensional que puede tomar generaciones" (pp. 183). La promoción de la reconciliación en un contexto como el colombiano se traduce en un largo y exigente proceso a fin de sanar las heridas y reconstruir el tejido social y las relaciones sociales en los distintos ámbitos y niveles de la sociedad. Esto no se resuelve con un par de talleres y algunas sesiones de apoyo psicosocial, que, aun cuando se deben llevar a cabo, requieren, además, de una estrategia sostenida que permita los cambios estructurales, institucionales y culturales, que conduzcan al ajuste de cuentas de la sociedad con su pasado doloroso y difícil.

En tercer lugar, en el camino hacia la reconciliación, se pueden identificar distintos estadios o fases de reconstrucción del tejido social y sanación de las heridas:

- Una condición inicial: hay que parar la violencia, asegurar la paz. Es muy difícil avanzar hacia la reconciliación en medio de la guerra, cuando la violencia sigue generando víctimas y afectando a la sociedad en general (de Roux, 2018, pp. 33-57; Rigby, 2001, pp. 183).

- Un primer estadio o fase: implica el reto de reemplazar el miedo por la coexistencia (política) no-violenta (Huyse, 2003, pp. 19).

- Un segundo estadio o fase: cuando el miedo no es el que domina, es posible comenzar a construir confianza y credibilidad (p. 20). 
- Un tercer estadio o fase: el tercer estadio de reconciliación se caracteriza porque se alcanza un estado de empatía entre los antiguos enemigos (p. 21).

Los autores del Manual de la reconciliación después de un violento conflicto no consideran en ningún momento el reto del perdón como un componente en el proceso de reconciliación. Personalmente, me distancio de la posición del manual en este punto: considero que no es posible alcanzar un nivel de empatía entre víctima y victimario, si no se ha pasado por alguna forma de perdón. Una víctima solo puede sentir empatía por su victimario si la ha perdonado. "Mediante el perdón, la víctima se libera de su sufrimiento, de su afán de venganza, de su relación dolorosa con el victimario, en una palabra, de su condición de víctima” (Galo Bilbao, 1999, p. 30).

En cuarto lugar, es importante resaltar que, estos estadios y fases de la reconciliación no se dan (necesariamente) en una secuencia de pasos tipo marco lógico, en la que el resultado ineludible es la reconciliación. Para entender realmente la reconciliación y la sanación social, hay que ir más allá de las nociones de cambio lineares secuenciales: se requiere un cambio de metáforas, que pasan de una perspectiva secuencial lineal a una de simultaneidad espacial. Hoy en día, en las metáforas dominantes de las ciencias sociales, hay una comprensión del conflicto como algo linear y de la paz como algo secuencial (Lederach y Lederach, 2010, pp. 41-68). Sin embargo, la experiencia que los Lederach han vivido en distintos contextos conflictivos, incluido Colombia, los ha llevado a la convicción de que, para entender realmente la reconciliación y la sanación social, se debe ir más allá de las nociones de cambio lineares secuenciales y mirar los aspectos más ocultos que estas implican como la circularidad, la simultaneidad y la multidireccionalidad.

Esta experiencia de circularidad, simultaneidad espacial y multidireccionalidad se puede encontrar en múltiples procesos de construcción 
de paz y reconciliación en Colombia, particularmente, a nivel de comunidades y víctimas, que han emprendido la ardua tarea de retejer las relaciones y hacer posible una coexistencia, en la que la confianza y la credibilidad en el otro sean posibles, a pesar de la continuidad de factores difíciles y muchas veces violentos. Este es el reto de construir paz en medio del conflicto (de Roux, 2018, pp. 75-103; 141-177).

Las comunidades locales se enfrentan al desafío actual de cómo alimentar espacios para la sanación y la reconciliación no como productos posteriores a la violencia, sino, como se desprende de su propia experiencia, como innovaciones permanentemente disponibles y desafiantes que deben dar a luz y renacer en condiciones lejanas de lo ideal (Lederach y Lederach, 2010, pp. 53).

\section{Conclusión}

Una paz sostenible y duradera solo es posible de alcanzar cuando se ha hecho el esfuerzo de promover la reconciliación en toda la complejidad que esta implica. Por doquier, las experiencias muestran que hay razones suficientes para comprometernos con esta tarea y que tenemos a mano los desarrollos conceptuales que nos permiten responder a la complejidad y niveles necesarios para promover la reconciliación, tras un conflicto largo y degradado. El reto es poder involucrar a toda la sociedad en dicha empresa de manera más amplia, sin perder de vista la prioridad que tienen las víctimas en la sanación y reconstrucción del tejido social. Se requiere, entonces, precisar el modelo de reconciliación que se ajuste más a las rupturas producidas por un conflicto específico como el colombiano e identificar los diversos estadios por los que esta puede pasar, sin olvidar la circularidad, simultaneidad espacial y multidireccionalidad, que muchas veces suponen los esfuerzos colectivos, particularmente, aquellos de las víctimas, para hacer posible una vida reconciliada para todos. 


\section{Referencias}

Acnur (2018). Tendencias globales: desplazamiento forzado en 2017. Ginebra: Acnur. Recuperado de: http://www.unhcr.org/statistics

Angulo Novoa, Alejandro (2015). Espiritualidad y construcción de paz. En Reconciliación, perspectivas y aportes conceptuales para su comprensión. Bogotá: Cinep/PPP/Berghof Foundation/sJR-Colombia.

Appleby, R. Scott (2000). The ambivalence of the sacred. Religion, violence and reconciliation. Lanham/Oxford: Rowman y Littlefield Publisher, Inc.

Bilbao, Galo (1999). Perspectiva filosófica del perdón. En: Galo Bilbao y otros, El perdón en la vida pública. Bilbao: Universidad de Deusto.

Bloomfield, David; Barnes, Teresa y Huyse, Luc (Eds.) (2003). Reconciliation after a violent conflict. A handbook. Stockholm: IDEA.

Bloomfield, David (2006). On good terms: clarifying reconciliation. Berlín: Berghof Center. Publicado en español en 2015: Clarificando términos: ¿qué podemos entender por reconciliación? En: Reconciliación, perspectivas y aportes conceptuales para su comprensión. Bogotá: Cinep/PpP/Berghof Foundation/SJR-Colombia.

Bloomfield, David (2016). Rehabilitating reconciliation. En Accord Insight, 3, pp. 45-47.

Centro de Memoria Histórica (2018). 262.197 muertos dejó el conflicto armado. Recuperado de: https://bit.ly/2LTgUQN

Cinep/Ppp (1990-2017). Banco de datos de actores y dinámica del conflicto. Bogotá: Cinep/PPP.

Compañía de Jesús (2008). Congregación General 35. Roma/Bilbao: Ediciones Mensajero/Sal Terrae.

Compañía de Jesús (2017). Congregación General 36. Bilbao/Bogotá: Grupo de Comunicación Loyola/Comunicaciones Jesuitas Colombia.

De Roux, Francisco (2018). La audacia de la paz imperfecta. Bogotá: Ariel.

García Durán, Mauricio (2006). Movimiento por la paz en Colombia 1978-2003. Bogotá: Cinep/PNUD/Colciencias. 
García Durán, Mauricio (2017). Retos para la reconciliación en Colombia. En: Vida Nueva-Colombia, 167, pp. 23-30.

Huyse, Luc (2003). The process of reconciliation. En: David Bloomfield, Teresa Barnes y Luc Huyse (Eds.), Reconciliation after a violent conflict. A handbook. Stockholm: IDEA.

Lederach, John Paul (1998). Reconciliación: La construcción de relaciones. En: John Paul Lederach, Construyendo paz. Reconciliación sostenible en sociedades divididas. Bilbao: Bakeaz/Gernika Gogoratuz.

Lederach, John Paul (2002). Five qualities of practice in support of reconciliation processes. En: Raymond G. Helmick S.J. y Rodney L. Petersen (Eds.). Forgiveness and reconciliation. Religion, public policy and conflict transformation. West Conshohocken: Templeton Foundation Press.

Lederach, John Paul (2003). The mystery of transformative times and spaces. En: Mary A. Cejka y Thomas Bamat (Eds.). Artisans of peace. Grassroots peacemaking among Christian communities. Maryknoll: Orbis Books.

Lederach, John Paul (2008). La imaginación moral. El arte y el alma de construir la paz. Bogotá: Grupo Editorial Norma.

Lederach, John Paul y Lederach, Angela Jill (2010). When blood and bones cry out. Journeys through the Soundscape of Healing and Reconciliation. Oxford, N. Y.: Oxford University Press.

Orozco Abad, Iván (2005). Sobre los límites de la conciencia humanitaria. Dilemas de la paz y la justicia en América Latina. Bogotá: Ed. Temis y Universidad de Los Andes.

Pécaut, Daniel (2001). Guerra contra la sociedad. Bogotá: Editorial PlanetaEspasa Hoy.

Philpott, Daniel (2012). Just and unjust peace. An ethic of political reconciliation. New York: Oxford University Press.

Pope, Stephen (2013). Modelos de la reconciliación. En: Recreando relaciones justas. Profundizando la misión de la reconciliación en el JRS. Roma: JRS/ Boston College.

Rigby, Andrew (2001). Justice and reconciliation after the violence. Boulder/ London: Lynne Rienner Publishers. 
Salter, Mark (2016). Joint analysis workshop report on peacebuilding and reconciliation. Accord Insight 3 Project. Recuperado de: https://bit.ly/2C5kRev

Salter, Mark y Yousuf, Zahbia (Eds.) (2016). Making peace with the past: transforming broken relationships. Accord Insight, 3. London: Conciliation Resources.

Schreiter, Robert J. (2000). El ministerio de la reconciliación. Espiritualidad y estrategias. Santander: Editorial Sal Terrae.

Schreiter, Robert J. (2014). Migrants and the ministry of reconciliation. En Daniel G. Groody y Gioacchino Campese, A Promised Land, a Perilous Journey. Theological Perspectives on Migration. Notre Dame: University of Notre Dame Press.

Villa, Juan David (2014). Recordar para reconstruir. Medellín: Universidad San Buenaventura.

Yoder, Carolyn (2005). The little book of trauma healing. Intercourse (PA): Good Books. 